\title{
Stereotype Ojek Pangkalan dalam Iklan Grab Bike
}

\author{
Shabrina Andani \\ Program Studi Ilmu Komunikasi, Universitas Muhammadiyah Yogyakarta \\ shabrinaandani@gmail.com \\ Meissy Sakina Firdausa \\ Program Studi Ilmu Komunikasi, Universitas Muhammadiyah Yogyakarta \\ Sakinah230500@gmail.com \\ Diserahkan: 8 Mei 2020; Direvisi: 26 Maret 202 1; Diterima: 26 Maret 2021
}

\begin{abstract}
This research was conducted to analyze advertisements that are still not in accordance with the prevailing advertising ethics because these advertisements contain elements of discrimination against a party, and present several scenes that are not suitable for the general public to consume. Discriminatory action is not appropriate in an advertisement, because it is tantamount to bringing down a party for personal gain. This study looked at how the Grab Bike \#PilihAman advertisement was considered discriminatory and formed new stereetypes for motorcycle taxis. This type of research used in this research is descriptive qualitative with a critical paradigm. This analysis was carried out through the signs that appeared in the advertisement, such as a discriminatory element to the base motorcycle taxi through the voice over of the advertisement, snippets of scenes that were not suitable to be shown. Based on the results of the analysis, Grab Indonesia builds a stereotype from the public towards pangkalan ojegs that they are unsafe and can harm their customers.
\end{abstract}

Keywords: Grab Bike, Motorcycles Base, Stereotype.

\begin{abstract}
Abstrak
Penelitian ini dilakukan untuk menganalisis iklan yang masih tidak sesuai dengan etika periklanan yang berlaku karena iklan tersebut mengandung unsur diskriminatif terhadap suatu pihak, serta menampilkan beberapa adegan yang tidak layak untuk dikosumsi khalayak ramai. Tindakan diskriminatif tidak layak dilakukan dalam sebuah iklan, karena sama saja dengan menjatuhkan suatu pihak demi kepentingan pribadi. Penelitian ini melihat bagaimana iklan Grab Bike \#PilihAman yang dianggap diskriminatif dan membentuk steretip baru terhadap ojek pangkalan. Jenis penelitian yang digunakan dalam penelitian ini adalah deskriptif kualitatif dengan paradigma kritis. Analisis ini dilakukan melalui tandatanda yang muncul dalam iklan tersebut seperti adanya unsur diskriminatif terhadap ojek pangkalan melalui voice over iklan tersebut cuplikan adegan-adegan yang tidak layak ditayangkan. Berdasarkan hasil analisis, Grab Indonesia membangun stereotip masyarakat terhadap ojek pangkalan bahwa ojek pangkalan itu tidak aman dan dapat mencelakai para pelanggannya.

Kata Kunci: Grab Bike, Ojek Pangkalan, Stereotip.
\end{abstract}




\section{PENDAHULUAN}

Iklan atau dalam bahasa Indonesia formalnya pariwara adalah segala bentuk pesan promosi benda seperti barang, jasa, produk jadi, dan ide yang disampaikan melalui media ditunjukan kepada sebagian besar masyarakat. Iklan ojek online Grab Indonesia adalah salah satu pesan promosi perusahaan jasa yang berawal dari layanan transportasi, namun kini Grab Indonesia telah mempunyai layanan lain seperti pengantaran makanan dan pembayaran yang bisa diakses lewat aplikasi mobile. Namun adanya perusahaan yang memiliki layanan mirip dengan Grab Indonesia mengharuskan perusahaan ini menunjukkan ke unggulannya ke khalayak umum. Hal ini mendorong perusahaan Grab untuk membuat iklan.

Grab Indonesia mengunggah video kampanye terbarunya yang berjudul \#PilihAman berdurasi 45 detik di berbagai social media miliknya. Video ini menarik perhatian publik dunia maya setelah menampilkan gambar seorang perempuan remaja bernama Dinda yang menggunakan ojek pangkalan mengalami kecelakaan dan menjadikannya penuh luka dan darah. Video iklan dalam kampanye \#PilihAman dari Grab menuai kecaman dari netizen, karena iklan ini dianggap Grab terlalu memandang sebelah mata para ojek pangkalan, salah satu saingan Grab Bike. Alasan lain yang membuat para netizen protes adalah karena dalam video iklan Grab, luka yang diderita oleh Dinda (sang penumpang) terlalu mengerikan untuk dikonsumsi umum terutama anak - anak (Vita, Nasrianti, Fitri, 2016)

Video ini kemudian mendapatkan respon dari pemerhati iklan. Seperti yang dikuti dari portal berita cnnindonesia.com, Ketua Tim Perumus Etika Parwira Indonesia, Hery Margono, menilai iklan terbaru Grab Indonesia ini berpotensi melanggar kode etik parwira periklanan yang ada. Setidaknya ada dua potensi pelanggaran kode etik yang ditampilkan iklan tersebut. Dua potensi pelanggaran itu berupa menimbulkan rasa takut dari hasil kekerasan dan merendahkan produk pihak lain. Dan menurut pemerhati industri iklan Indonesia. Ridwan Sanjoyo, menilai iklan yang di tampilkan di media sosial itu telah melanggar etika periklanan di Indonesia. Salah satunya adalah visualisasi iklan yang menampilkan perempuan yang berdarah - darah (Vita, 2017). Kini masyarakat sudah banyak yang menggunakan ojek online, dikarenakan lebih praktis dibandingkan dengan ojek pangkalan. Hal ini membuat kecemburuan dari ojek pangkalan, karena banyak konsumen dari ojek pangkalan yang berpindah menggunakan ojek online.

\section{KAJIAN PUSTAKA}

Iklan dapat diartikan sebagai sesuatu yang dapat mempengaruhi masyarakat. Maka dari itu, inti dari periklanan terletak pada bagaimana usaha mengalihkan khalayak agar memperhatikan pada sesuatu yang ingin menjadi tujuan kita (Muktaf, 2015) dan mempengaruhinya. Selain fungsi iklan yang mengalihkan perhatian dan mempengaruhi masyarakat berarti bahwa iklan tidak hanya bersifat memberi informasi, lebih dari itu iklan memiliki kemampuan yang potensial dalam menyatakan bahwa produknya lebih unggul dari produk lainnya. Walaupun pada umumnya orang tidak ingin dibujuk atau didorong untuk membeli produk yang sudah jelas dapat memuaskan kebutuhan dan keinginan mereka. Orang sering mengatakan iklan adalah media mempromosikan suatu produk (Fauziah \& Puspita, 2018).

Semua iklan tentunya memiliki tujuan yang sama yaitu mempengaruhi dan dapat diterima oleh para konsumen. Dengan ini, iklan seharusnya berisi pesan yang positif agar persepsi konsumen yang melihat iklan itupun baik. Namun persepsi masyarakat pada sebuah iklan dapat bersifat positif maupun negatif. Iklan dengan persepsi positif menimbulkan pembelian yang disebabkan oleh informasi produk yang jelas dan rinci (Hakim \& Susilowati, 2013). Maka persepsi negatif diasumsikan kebalikannya.

Dari penjelasan diatas, sebenarnya apa maksud dari persepsi? Persepsi adalah pengalaman tentang objek, peristiwa, atau hubungan-hubungan yang diperoleh dengan menyimpulkan informasi dan menafsirkan pesan, yang kemudian memberikan makna pada stimulus inderawi (Rakhmat, 2013). 
Proses terjadinya persepsi yaitu apabila objek menimbulkan stimulus dan stimulus mengenai alat indera atau reseptor (Walgito, 2004).

Perlu diketahui, media online berkemungkinan besar menjadi sasaran bagi para pengiklan untuk mengiklankan suatu produk atau jasa. Media online sendiri merupakan sarana komunikasi yang tersaji secara online dan dapat dijangkau oleh siapapun dan dimanapun. Namun, masih banyaknya iklan di media online yang tidak sesuai dengan etika periklanan. "Consumers believe advertising often violates broad ethical norms. In addition, the degree to which consumers judge advertising as ethical or unethical varies as a function of their relativism and idealism," (Triesie, Weigold, Conna, \& Garrison, 1994). Pernyataan tersebut menekankan bagaimana konsumen merasa bahwa sering kali iklan bersifat tidak etis, hal ini mengasumsikan bagaimana sebuah persepsi negatif publik terhadap sebuah iklan timbul dikarenakan publik merasa iklan tersebut telah melanggar beberapa nilai-nilai etika.

Hal ini mengakibatkan iklan yang diciptakan malah tidak bisa diterima oleh para konsumen dan mengakibatkan terjadinya sebuah krisis untuk perusahaan yang menciptakan iklan tersebut. Krisis secara umum dapat disebabkan oleh dua sumber, yaitu dari dalam dan dari luar organisasi. Sumber krisis dari dalam organisasi antara lain: manusia, manajemen, dan teknologi. Sumber dari luar, yaitu peraturan-peraturan pemerintah, bencana alam, dan kerusakan yang dilakukan oleh orang lain (malevolent) (Kriyantono, Rachmat, 2012).

Salah satu iklan yang tidak bisa diterima oleh para konsumen dan menimbulkan sebuah citra buruk perusahaannya adalah iklan dari Grab Bike Indonesia yang dikenal dengan hashtag \#PilihAman dan ditayangkan di media online Youtube. Iklan ini menuai banyak kecaman dari berbagai kalangan khalayak yang menontonnya dikarenakan iklan ini mengandung unsur diskriminatif. Hal ini terjadi karena terjadinya krisis yang bersumber dari dalam organisasi yaitu kurangnya pengawasan dalam penciptaan iklan \#PilihAman ini. Sebuah iklan sebenarnya harus bersifat positif dan tidak bersifat diskriminatif. Namun iklan Grab Bike Indonesia ini mendiskriminasi pihak ojek pangkalan, dengan menampilkan seorang wanita yang terluka apabila dia menggunakan jasa ojek pangkalan. Iklan tersebut dapat membuat perspektif konsumen terhadap ojek pangkalan menjadi buruk.

\section{METODE PENELITIAN}

Jenis penelitian yang digunakan dalam penelitian ini adalah deskriptif kualitatif dengan paradigma kritis. Secara operasional, penelitian ini menggunakan metode semiotika untuk menganalisis obyek penelitian. Obyek penelitian dalam penelitian ini adalah iklan Grab Bike Indonesia \# PilihAman versi Youtube tahun 2016, iklan ini berupa video yang berdurasi 50 detik. Obyek penelitian ini dianalisis dengan menggunakan analisis semiotika Roland Barthes yang mengembangkan pemikiran dari Ferdinand De Saussure.

Pertama, tanda (sign) terdiri dari dua aspek, yaitu penanda (signifiant), dan petanda (signified). Penanda dapat dimengerti sebagai bentuk/wujud fisik. Penanda bisa berupa bunyi, gambar, huruf, visual dan sejenisnya, sedangkan petanda adalah konsep atau arti dari apa yang ditandai. Relasinya antara keduanya bersifat "diada-adakan" (arbitrary), yang berarti tidak ada relasi yang sifatnya alamiah antara penanda dan petanda. Namun demikian, relasi yang bersifat "diada-adakan" terikat oleh konvensi atau struktur.

Secara etimologis, Saussure menyebutkan bahwa semiotika sebagai ilmu yang mengkaji tentang tanda sebagai bagian dari kehidupan sosial (Piliang, 2003). Selanjutnya Saussure, semiotika kemudian dielaborasi sebagai hubungan tripartit yakni tanda (sign) yang merupakan gabungan dari penanda (signifier) dan petanda (signified) (Fiske dan Hartley, 1996).

Kedua, langue dan parole. Langue merupakan abstraksi dan artikulasi bahasa pada tingkat sosial budaya, sedangkan parole merupakan ekspresi bahasa pada tingkat individu. Langue bisa kita sebut sebagai sistem bahasa yang berlaku, sedangkan parole adalah bagaimana individu berbahasa dalam sistem tersebut 


\begin{tabular}{l|l}
$\begin{array}{l}\text { 1. Signifier } \\
\text { (Penanda) }\end{array}$ & $\begin{array}{c}\text { 2. Signified } \\
\text { (Petanda) }\end{array}$ \\
\cline { 1 - 1 } Denotatif Sign (Tanda Denotatif) & \\
\hline $\begin{array}{l}\text { 4. CONNOTATIF SIGNIFIER } \\
\text { (PENANDA KONOTATIF) }\end{array}$ & $\begin{array}{c}\text { 5. CONNOTATIF SIGNIFIED } \\
\text { (PETANDA KONOTATIF) }\end{array}$ \\
\hline
\end{tabular}

\section{CONNOTATIF SIGN (TANDA KONOTATIF)}

\section{Gambar 1. Pemaknaan Tanda dalam Semiotika Roland Barthes}

Roland Barthes melanjutkan pemikiran Saussure dengan memberi telaah pada interaksi antara teks dengan pengalaman personal dan kultural penggunanya. Interaksi antara konvensi dalam teks dengan konvensi yang dialami dan diharapkan oleh penggunanya. Gagasan Barthes ini dikenal dengan tatanan penandaan (order of signification), yang mencakup primary signification atau denotasi (makna sebenarnya sesuai kamus) dan secondary signification atau konotasi (makna ganda yang lahir dari pengalaman kultural dan personal). Makna konotasi inilah yang kemudian menjadi berkembang menjadi mitos. Dalam penelitian ini, penulis berusaha melakukan analisis semiotika, mulai dari primary signification sampai secondary signification pada iklan Grab Bike Indonesia \#PilihAman.

\section{HASIL DAN PEMBAHASAN}

Iklan ini menggunakan puffery (pujian yang berlebihan) dalam menekankan kebenaran. Jamieson dan Campbell (1988) menyebutkan enam cara iklan menekankan kebenaran yaitu (1) pseudo-claims, (2) comparison with an unidentified other, (3) comparisons of the product to its earlier form, (4) irrelevant comparisons, (5) pseudo-survey dan (6) juxtaposition (Potter, 2014).

Pseudo-claims, merupakan klaim yang diciptakan oleh pengiklan namun tidak diinformasikan bagaimana klaim tersebut dilakukan, hal ini terjadi pada voice over iklan video kampanye Grab \#PilihAman yang mengklaim tiga hal: (a) Pelatihan Keselamatan dengan tulisan verbal tambahan di bagian akhir: "Pengemudi Grab Bike 100\% lulus pelatihan keselamatan berkendara"; (b) Dokumen lengkap; dan (c) Motor dirawat rutin.

Comparison with an unidentified other, dilakukan ketika pengiklan melakukan perbandingan dengan pihak lain yang tidak diidentifikasikan, hal ini terjadi saat Grab membandingkan dengan pihak ojek pangkalan. Comparisons of the product to its earlier form, ini merupakan salah satu cara pengiklan menekankan peningkatan pada produknya ketika dibandingkan dengan produk lamanya.

Irrelevant comparisons, merupakan perbandingan yang dilakukan oleh pengiklan yang kurang relevan. Hal ini terjadi pada voice over yang mengatakan bahwa Dinda memilih yang benar. Sedangkan tidak dijelaskan mana pilihan yang salah. Sehingga objek perbandingannya tidak relevan dan tidak bisa dibuktikan kebenarannya. Pseudo-survei adalah ketika pengiklan menyatakan bahwa produk yang diiklankan telah melewati beberapa survei. Namun tidak diinformasikan survei seperti apa.

Cara yang terakhir adalah juxtaposition. Juxtaposition adalah ketika pengiklan menampilkan seseorang yang dapat menghasilkan asumsi bahwa orang tersebut bahagia dan puas saat memilih dan menggunakan produk tersebut. Cara ini digunakan pada adegan terakhir saat aktris yang bernama Dinda memilih Grab dan ketika aktris tersebut berkendara diatasnya sebagai penumpang, ia terlihat tersenyum yang mengasumsikan bahwa ia senang dan puas telah memilih sebuah pilihan yang bener.

Hal ini mendorong adanya penelitian ini yang bertujuan untuk menjelaskan bagaimana khalayak melihat video kampanye iklan Grab Bike \#PilihAman ini sebagai iklan yang tidak pantas ditayangkan. 


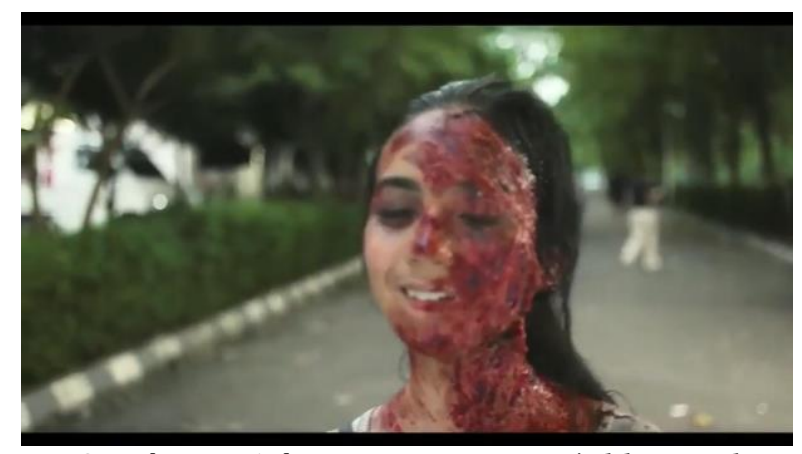

Gambar 2. Adegan yang Menunjukkan Luka dan Darah

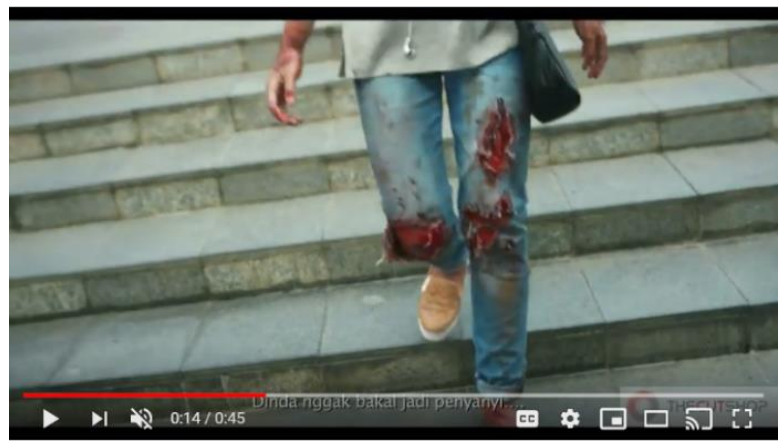

Gambar 3. Adegan yang Menunjukkan Luka dan Darah

Pada iklan Grab Bike \#PilihAman ini diceritakan bahwa ada wanita yang sedang berjalan di kampusnya dengan voice over seorang laki paruh baya dan subtitle yang berbunyi "Ini Dinda, anak saya. Umurnya 20 tahun dan dia pengen jadi penyanyi. Sebentar lagi dia harus ambil keputusan besar.”. Tepat setelah adegan itu, lebih tepatnya pada detik 10 di wajah dan tubuh Dinda mulai bermunculan luka luka yang sangat banyak dan mengerikan dengan voice over dan subtitle yang berbunyi "Kalau salah pilih, Dinda nggak bakal jadi penyanyi, nggak akan ketemu teman-temannya, Ibunya, atau saya lagi."

Seperti yang tertera pada gambar 2 dan 3 diatas, luka luka Dinda tidak di sensor dan terlihat sangat banyak dan mengerikan, hal ini menjadi buah bibir masyarakat karena dinilai iklan ini tidak pantas untuk ditayangkan. Hal ini juga disayangkan karena luka dan darah ini tidak baik dikonsumsi oleh mereka yang masih di bawah umur, apalagi bagi khalayak yang memiliki phobia darah atau hemophobia. Pada adegan ini, voice over yang terdengar pun membuat adegan ini menjadi semakin mengerikan.

Hal ini tentu saja dilarang dalam Etika Pariwara Indonesia pasal 1.8 yang berbunyi "Iklan tidak boleh menimbulkan atau mempermainkan rasa takut, ataupun memanfaatkan kepercayaan orang terhadap takhayul." Selain itu iklan yang menampilkan luka dan darah itu juga telah melanggar etika periklanan tentang Standar Program Siaran (SPS) pasal 23 B yang berisi tentang "Menampilkan manusia atau bagian tubuh yang berdarah-darah, terpotong-potong, dan/atau kondisi yang mengenaskan akibat dari peristiwa kekerasan."

\section{DISKRIMINATIF OJEK PANGKALAN SEBAGAI PENYEBAB KECELAKAAN LALU LINTAS}

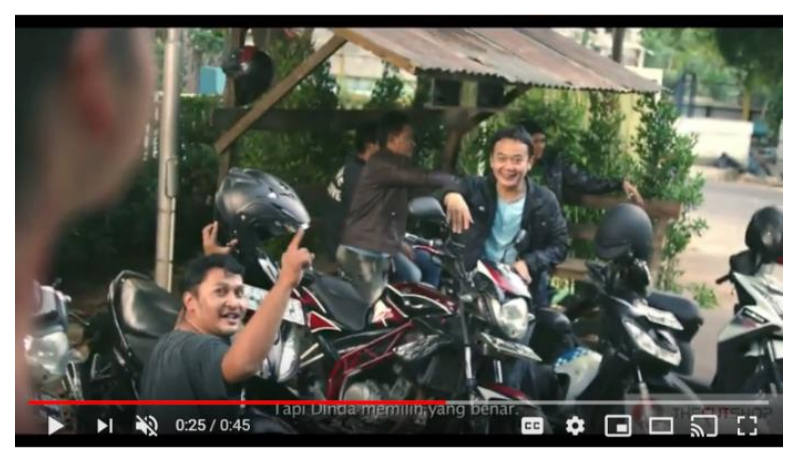

Gambar 4. Salah Satu Adegan yang Mendiskriminasi Ojek Pangkalan 
Pada detik 25 muncul adegan yang menampilkan beberapa lelaki yang sedang mengecek motornya menawarkan Dinda untuk menggunakan jasa antar menggunakan ojek mereka seperti yang terlihat pada gambar 4. Jika dihubungkan dengan adegan di detik sebelumnya yang menunjukkan luka-luka di wajah dan tubuh Dinda, iklan ini menunjukkan pesan tersirat yang kurang baik. Pesan tersiratnya yaitu jika menggunakan ojek pangkalan maka yang akan Dinda dapatkan adalah kecelakaan lalu lintas yang mengakibatkan Dinda mendapatkan luka luka yang sangat parah.

Netizen merasa pihak Grab Indonesia terlalu tinggi hati karena telah merendahkan pihak ojek pangkalan pada iklan ini. Selain itu netizen merasa pesan tersirat ini belum tentu benar adanya. Grab bike Indonesia dinilai masih kurang dalam menanggulangi kasus yang terjadi. Sebab, kurang adanya tindakan yang cepat terhadap video iklan ini yang tersebar pada 18 September 2016 diberbagai media sosial terutama pada akun youtube milik Grab Indonesia.

Dari gambar 2 dan 3 diatas dapat kita lihat bahwa diperlihatkan seorang wanita bernama Dinda memiliki wajah yang terluka dan penuh darah ditayangkan dengan sangat jelas oleh pihak Grab Indonesia dan tidak di sensor. Pengiklan bukan tidak memiliki alasan untuk membuat iklan seperti itu, pihak Grab Indonesia bermaksud membuat anggapan orang bahwa apabila seseorang menggunakan ojek pangkalan tidak akan menjamin keselamatan mereka sehingga akan terjadi hal seperti yang ada di iklan tersebut, pihak Grab Indonesia bermaksud untuk menyakinkan masyarakat bahwa dengan menggunakan Grab Bike jauh lebih aman dan terpercaya dibandingkan ojek pangkalan. Padahal tayangan seperti ini merupakan salah satu bentuk pelanggaran.

Semenjak adanya transportasi online Grab Bike di Indonesia muncul mitos yang berkembang bahwa ojek pangkalan itu tidak aman dan membahayakan konsumennya karena para ojek pangkalan tidak ada pelatihan pekerjaan, sedangkan ojek online dianggap terjamin aman, tidak membahayakan konsumen karena sudah mendapat pelatihan sebelumnya dan kendaraan yang mereka gunakan sesuai dengan Standar Operasional Prosedur (SOP).

Sebuah iklan dikatakan tidak etis jika memiliki upaya menjatuhkan pesaing lainnya. " $A n$ advertisement is considered to be unethical if it attempts to damage the competitors' product or service and conveying wrong or misleading information, making overstated claims, and effects people lives in a negative manner," (Huq, Nekmahmud, \& Aktar, 2016). Dengan demikian, visualisasi yang memperlihatkan priapria yang menawarkan Dinda yang merupakan simbol ojek pangkalan ini dianggap tidak etis, karena secara vulgar menjatuhkan pesaing dari Grab itu sendiri.

Di dalam Etika Pariwara Indonesia pun sudah diatur sedemikian rupa pada pasal 1.20 yang berbunyi "Iklan tidak boleh merendahkan produk pesaing," agar tidak terjadi persaingan tidak sehat antara brand satu dengan yang lainnya.

\section{KESIMPULAN}

Iklan berfungsi untuk mengalihkan perhatian dan mempengaruhi masyarakat agar tertarik pada suatu produk, ini mengartikan bahwa iklan tidak hanya bersifat memberi informasi, tetapi lebih dari itu, iklan memiliki kemampuan yang potensial dalam menyatakan bahwa produknya lebih unggul dari produk lainnya, sehingga tak sedikit para pengiklan melakukan berbagai cara dan menghasilkan berbagai ide agar para konsumen dapat terpengaruh. Tak jarang iklan itupun tidak sesuai dengan etika periklanan yang berlaku, salah satunya pada iklan ojek online Grab Bike \#PilihAman diatas yang menuai kontroversi karena secara tersirat pihak Grab Indonesia ini sudah melakukan diskriminasi terhadap ojek pangkalan, dengan model iklan yang terlihat terluka akibat menggunakan ojek pangkalan, hal ini dapat membangun stereotip masyarakat terhadap ojek pangkalan bahwa ojek pangkalan itu tidak aman dan dapat mencelakai para pelanggannya. Iklan itupun juga tak seharusnya dikonsumsi oleh anak dibawah umur dan para hemophobia karena memperlihatkan bagian-bagian tubuh yang terluka dan berdarah-darah, hal tersebut dapat mengganggu psikologis mereka. 


\section{REFERENSI}

Aditya Vita; Nasrianti, Lisdian Fitri (2016). KOMUNIKASI KRISIS DI SOSIAL MEDIA: Analisis Manajemen Krisis Iklan \#PilihAman Grab Bike Indonesia. Bandar Lampung, Universitas Lampung

Bertens, K. (2000). Pengantar Etika Bisnis. Yogyakarta, Kansisus

Muktaf, Z. M. (2015). PERIKLANAN: Sebuah Pendekatan Praktis. Yogyakarta, Buku Litera.

Kriyantono, Rachmat (2012). Public Relations \& Crisis Management Pendekatan Critical Public Relations, Etnografi Krisis \& Kualitatif. Jakarta, Kencana Prenada Media Group.

Huq, S. M., Nekmahmud, M., \& Aktar, M. S. (2016). Unethical practices of advertising in bangladesh: a case study on some selective products. International Journal of Economics, Finance and Management Sciences, 4(1), 10-19.

Fauziah, D., \& Puspita, R. (2018). Analisis semiotika john fiske mengenai realitas bias gender pada iklan kisah ramadhan line versi adzan ayah. ProTVF: Jurnal Kajian Televisi Dan Film, 2(2), 157171.

Hakim, R. T., \& Susilowati, C. (2013). Pengaruh persepsi iklan, kesadaran merek, citra merek terhadap sikap pada merek dan keputusan pembelian (studi pada produk pestisida merek sidamethrin 50 EC). Jurnal Aplikasi Manajemen, 11(4), 537-546.

Triesie, D., Weigold, F. M., Conna, J., \& Garrison, H. (1994). Ethics in advertising: ideological correlates of consumer perceptions. Journal of Advertising, 23(3), 59-69.

Potter, W. J. (2014). Media literacy. Los Angeles: SAGE.

Walgito, B. (2004). Pengantar psikologi umum. Yogyakarta: Andi.

Rakhmat, J. (2013). Psikologi komunikasi. Bandung: Remaja Rosdakarya 